\title{
Identidade e os profisssionais de comunicação: Aproximações teóricas entre o processo de identificação e a comunicação nas organizações ${ }^{1}$
}

\section{Identity and the communication professionals: Theoretical approaches between the identification process and communication in organizations}

\author{
DOI: $10.46814 / \operatorname{lajdv3n2-019}$
}

Recebimento dos originais: 23/12/2020

Aceitação para publicação: 26/02/2021

\section{Bruno Carramenha}

Mestre em comunicação, professor na Fundação Armando Álvares Penteado (FAAP), em São Paulo/SP R. Alagoas, 903 - Higienópolis, São Paulo - SP, 01242-902

E-mail: bpcarramenha@faap.br

\section{RESUMO}

A partir do estudo da prática da comunicação no âmbito das organizações por meio de pesquisa bibliográfica da área de Relações Públicas, o presente artigo pretende relacionar os conceitos de identidade e identificação, advindos da sociologia, com as posições que os profissionais de comunicação corporativa têm assumido nas organizações. Por meio de um olhar histórico, objetiva-se investigar o processo de identificação do profissional no realizar de suas atividades, seja na gestão dos processos midiáticos organizacionais ou na liderança estratégica dos departamentos de comunicação, com base nas interpelações dos executivos com quem se relaciona profissionalmente ou da própria categoria da qual faz parte.

Palavras-Chave: Identidade, Identificação, Comunicação corporativa, Comunicação com empregados. Processos midiáticos.

\begin{abstract}
From the study of the practice of communication within organizations through bibliographic research in the area of Public Relations, this paper aims to relate the concepts of identity and identification, derived from sociology, with the positions that corporate communication professionals have assumed in organizations. By means of a historical look, it aims to investigate the process of identification of the professional in the performance of his activities, whether in the management of organizational media processes or in the strategic leadership of communication departments, based on the interpellations of the executives with whom he relates professionally or of the category of which he is a part.
\end{abstract}

Key-words: Identity, Identification, Corporate Communication, Communication with employees. Media Processes.

\section{INTRODUÇÃO}

O desenvolvimento e a prática da comunicação nas empresas se confundem com o próprio estabelecimento das estruturas organizacionais. Tomando-se por base que a comunicação é o fundamento das relações humanas (MARCHIORI, 2008), é, portanto, indispensável no funcionamento das organizações, que são "sistemas sociais e históricos, constituídos por recursos materiais e imateriais e

\footnotetext{
${ }^{1}$ Trabalho apresentado na no XIV Congresso Internacional IBERCOM, na Universidade de São Paulo, São Paulo, de 29 de março a 02 de abril de 2015.
} 
pessoas - que se comunicam e se relacionam entre si” (NASSAR, 2009, p. 62).

A partir da metade do século XX, entretanto, as organizações passaram a sentir a necessidade de gerenciar seus relacionamentos com públicos diversos e de dar conta formalmente dos processos midiáticos corporativos e, portanto, a tratar a comunicação sob uma perspectiva funcional, neste caso, tendo a necessidade de um profissional para este gerenciamento. Este profissional, por sua vez, como qualquer indivíduo contemporâneo, está sujeito às mazelas do tempo em que vive.

As organizações são um "produto da história e do tempo das sociedade em que se inserem" (FREITAS, 2006, p.55) e estão, portanto, suscetíveis a sediar - e a participar ativamente - dos diversos processos aos quais os indivíduos estão sujeitos, como o processo de identificação daqueles que dela fazem parte.

Apegando-se temporariamente a posições diferentes, o sujeito contemporâneo está necessariamente submetido a um processo de identificação, ora por si próprio ora pelas pessoas a sua volta. Submetida a um processo - diga-se, que nunca será acabado - a identidade do sujeito está sempre em formação, em andamento, construindo-se a partir de uma busca prioritariamente externa para completar aquilo que lhe falta internamente.

Este processo tem relação, prioritariamente, com aquilo que o outro projeta sobre o indivíduo.

A concepção do sujeito sociológico é vista como uma concepção 'interativa' da identidade do eu, em que o sujeito ainda continua tendo um núcleo ou uma essência identitária interior que é chamada de 'eu real', mas esta é formada e modificada na 'interação' entre o eu e a sociedade (VIEIRA, 2021).

No contexto organizacional, está o profissional de comunicação, que precisa se afirmar em posições e representações por meio de um processo sem-fim de identificação.

A partir do estudo da comunicação organizacional por meio de pesquisa bibliográfica da área de Relações Públicas (CARRAMENHA, CAPPELLANO e MANSI, 2013; FERNANDES, 2011; FERRARI, 2009; KUSCH, 2002, 2003, 2009; MARCHIORI, 2008, 2010; NASSAR, 2009), este artigo pretende relacionar os conceitos de identidade e identificação, advindos da sociologia (BAUMAN, 2001, 2005; HALL, 2013, 2014a, 2014b; WOODWARD, 2014), com o papel que os profissionais de comunicação corporativa têm assumido nas organizações. Acreditamos, como Ferrari (2009), que há uma confusão na prática - e, por conseguinte, no reconhecimento - da comunicação realizada nas organizações que contribuiu para uma perda de identidade da atividade.

Serão avaliados os aspectos históricos do surgimento da atividade de comunicação corporativa que contribuem para a formação da identidade da categoria profissional e, igualmente, dos indivíduos que ocupam estes postos nas organizações. O olhar para a história é relevante ao passo que nos permite compreender com mais clareza a realidade contemporânea. Nas relações que se faz da atividade de comunicação corporativa com o conceito de identidade, é importante mencionar que o próprio 
entendimento da identidade se transforma com a história, de acordo com as concepções de sujeito (GREGOLIN, 2008).

\section{ATUAÇÃO PROFISSIONAL DA COMUNICAÇÃO E A IDENTIDADE}

A Comunicação vem ganhando mais relevância nas organizações do que em décadas anteriores, especialmente por conta das grandes transformações sociais e tecnológicas que emergiram (FERRARI, 2009). As principais responsabilidades da disciplina enquanto departamento organizacional, no que tange a comunicação com empregados, variam significativamente dependendo do contexto organizacional, ainda que, academicamente destaque-se o forte vínculo e contribuição para o alcance dos objetivos organizacionais, promoção de clima positivo, por meio do alinhamento entre discurso e prática e geração de engajamento (CARRAMENHA; CAPPELLANO; MANSI, 2013).

Há duas perspectivas de análise da comunicação das organizações. Como um processo, a comunicação é estudada como agente de criação da realidade e do mundo social (MARCHIORI, 2008). “A organização depende da comunicação para sua sobrevivência" (MARCHIORI, 2008, p. 148).

Corrobora Kunsch com essa visão quando afirma que

o sistema organizacional se viabiliza graças ao sistema de comunicação nele existente, que permitirá sua contínua realimentação e sua sobrevivência. Caso contrário, entrará num processo de entropia e morte. Daí a imprescindibilidade da comunicação para uma organização social (2003, p. 69).

Nesta perspectiva, a comunicação é entendida como um processo, ou seja, ela cria a realidade e o mundo social (MARCHIORI, 2008). Desta forma, independem os modelos administrativos adotados pela gestão, uma vez que a comunicação se estabelece na dinâmica do dia a dia de trabalho, nas relações internas, na construção e no compartilhamento de significados entre empregados e empresa, na criação e disseminação de regras, regulamentos, procedimentos, direitos e deveres (NASSAR, 2009), que pode acontecer nos fluxos formais ou informais ${ }^{2}$ das organizações.

A comunicação, no entanto, também assume um caráter funcional, adquirindo um papel de servir um propósito nos processos de interação nas organizações (MARCHIORI, 2008). Neste caso, está sedimentada nos fluxos formais e tem relação direta com a gestão dos negócios. Nas organizações, comumente, este caráter funcional diz respeito ao que se atribui aos departamentos de Comunicação.

A prática da comunicação corporativa de maneira mais formal está diretamente relacionada à história das Relações Públicas no Brasil”. A partir da década de 50 "surgem os primeiros e efetivos

\footnotetext{
${ }^{2}$ Por fluxos formais entende-se a comunicação que se estabelece por meio dos canais institucionalizados da companhia e costuma ser disseminada verticalmente. Já os fluxos informais acontecem fora dos canais oficiais, de forma espontânea e usualmente de forma oral. (CARRAMENHA; CAPPELLANO; MANSI, 2013).

${ }^{3}$ O início da profissão de Relações Públicas no Brasil é reconhecido como tendo sido em 1914, com a criação do Departamento de Relações Públicas da Light, entretanto, essa experiência, apesar de pioneira, foi isolada, não ocorrendo
} 
departamentos de Relações Públicas nas empresas multinacionais e nas agências de Publicidade e Propaganda" (KUNSCH, 2002, p. 121) para lidar com uma demanda latente de estabelecimento de relações formais e estruturadas entre as organizações e seus públicos. É também, nesta mesma época, que surge o conceito de "Jornalismo Empresarial", que tratava exclusivamente da gestão dos processos midiáticos, por meio da produção de boletins institucionais e house organs. Antes disso, são poucos e sem representatividade os registros do uso funcional da comunicação nas organizações.

Não é à toa que as áreas correlatas de jornalismo e publicidade e propaganda tenham sido fundamentais na formação e consolidação da prática da comunicação nas organizações, uma vez que o primeiro curso universitário de Relações Públicas surgiu em 1967, 20 anos depois da fundação da faculdade de jornalismo e 16 anos depois da primeira escola superior de propaganda (HIME, 2004; DURAND, 2006).

A história ajuda a compreender a práxis. A pesquisa 'Comunicação Interna 2012', da Associação Brasileira de Comunicação Empresarial - Aberje (2012), revela que a vasta maioria (43\%) dos profissionais responsáveis pela Comunicação Interna nas organizações é formada em jornalismo. A formação em Relações Públicas está em segundo lugar, com menos da metade dos profissionais (21\%), seguida, de perto, por Publicidade e Propaganda (16\%). Esses dados são congruentes com pesquisa desenvolvida pela professora Maria Aparecida Ferrari (2009) em empresas da América Latina, que apontou, no Brasil, que entre as 22 empresas pesquisadas, oito delas tem um jornalista de formação na liderança do departamento de Comunicação. Três delas contam com um profissional de Relações Públicas e nas demais são profissionais de outras habilitações da comunicação, além de advogados, engenheiros, administradores, entre outros.

A pesquisa de Ferrari aponta ainda que

é comum a confusão que se estabelece [por parte da alta direção das organizações latinoamericanas] principalmente entre as profissões de relações públicas e jornalismo, com forte predominância da segunda sobre a primeira, uma vez que existe maior clareza em relação ao fazer jornalístico (FERRARI, 2009, p. 190).

A “confusão" tem outros fatores determinantes, além da formação universitária. Entre eles está a forma como o profissional se posiciona e é reconhecido na organização.

Uma constatação curiosa que fizemos foi a divergência entre as visões [...]. Enquanto quase a metade da amostra dos CEO's identificava o profissional de relações públicas com a função mediática e técnica, os comunicadores, na sua maioria, afirmavam exercer sua função na dimensão estratégica (FERRARI, 2009, p. 191).

maior crescimento nas três décadas seguintes. (KUSCH, 2002). 
Isto, acredita a pesquisadora, tem estreita relação com a realidade vivida pelo profissional de comunicação nas estruturas cada vez mais enxutas das organizações, que o forçam a desenvolver papéis altamente estratégicos e meramente operativos, por falta de recursos humanos (FERRARI, 2009).

Essa "troca de papéis" a qual o profissional de comunicação está sujeito nas organizações não é exclusiva aos comunicadores. Não é, aliás, exclusiva de quem está vinculado a organizações apenas - e tampouco está fadada a acontecer apenas no interior dos muros organizacionais. $\mathrm{O}$ apego temporário a diferentes representações é inerente ao sujeito contemporâneo. A ruptura da antiga concepção de que as condições humanas seriam divinamente estabelecidas - apoiadas, portanto, nas tradições - causou um deslocamento do sujeito e, portanto, uma fragmentação da identidade (HALL, 2014b).

As identidades que o sujeito assume se constroem por meio de práticas discursivas, a partir de um encontro entre a expectativa e interpelação alheia e os "processos que produzem subjetividades, que nos constroem como sujeitos aos quais se pode "falar"' (HALL, 2014a, p. 112), podendo o sujeito se reconhecer em múltiplas identidades, conforme a posição discursiva que ocupa ou a maneira pela qual é interpelado ou representado.

Assim, o sujeito se vê, constantemente, obrigado a oficializar em discurso uma resposta para a pergunta “Quem sou eu?", como se precisasse fazer essa afirmação ao outro para, de fato, ser.

\begin{abstract}
Afinal de contas, a essência da identidade - a resposta à pergunta “Quem sou eu?" e, mais importante ainda, a permanente credibilidade da resposta que lhe possa ser dada, qualquer que seja - não pode ser constituída senão por referência aos vínculos que conectam o eu a outras pessoas e ao pressuposto de que tais vínculos são fidedignos e gozam de estabilidade com o passar do tempo. Precisamos de relacionamentos, e de relacionamentos em que possamos servir para alguma coisa, relacionamentos aos quais possamos referir-nos no intuito de definirmos a nós mesmos (BAUMAN, 2005, p. 74).
\end{abstract}

Desta maneira, a identidade não pode ser entendida como algo que emerge naturalmente do indivíduo, mas sim como um processo contínuo, de formação ao longo do tempo. Portanto, recomenda Hall que "em vez de falar da identidade como uma coisa acabada, deveríamos falar de identificação, e vê-la como um processo em andamento" (2014b, p. 24), que, por operar por meio da différance, "envolve um trabalho discursivo, o fechamento e a marcação de fronteiras simbólicas” (2014a, p. 106).

\title{
3 IDENTIFICAÇÃO: UM PROCESSO EM CONSTRUÇÃO
}

No contexto organizacional, a demanda pela formalização e "funcionalização" da comunicação, por meio da gestão dos relacionamentos e dos processos midiáticos, fez surgir uma nova categoria de profissionais de comunicação corporativa, que assumiram a tarefa de liderar a área de Comunicação para a consecução dos seus objetivos. Dentro das organizações, estes profissionais, como tantos outros, estão sujeitos à dinâmica contemporânea que o trabalho assume na sociedade, e, igualmente, ao processo de identificação, advindo das interpelações que acontecem dentro e fora do ambiente organizacional, e que 
gera a fragmentação identitária.

O sujeito assume identidades diferentes em diferentes momentos, identidades que não são unificadas ao redor de um 'eu' coerente. Dentro de nós há identidades contraditórias, empurrando em diferentes direções, de tal modo que nossas identificações estão sendo continuamente deslocadas (HALL, 2014b, p. 12).

O processo de identificação do indivíduo se dá, muitas vezes, com grupos sociais que se faz - ou quer fazer - parte, a procura de um "nós" a que possa pedir acesso (BAUMAN, 2005). Assim, Woodward (2014) defende que o sujeito atenderá sempre às diferentes expectativas e restrições envolvidas nos campos sociais nos quais atua, especialmente em face à complexidade da vida moderna, que exige dele assumir diferentes identidades.

Os indivíduos vivem no interior de um grande número de diferentes instituições, que constituem aquilo que Pierre Bourdieu chama de 'campos sociais', tais como famílias, os grupos de colegas, as instituições educacionais, os grupos de trabalho ou partidos políticos. Nós participamos dessas instituições ou 'campos sociais', exercendo graus variados de escolha e autonomia, mas cada um deles tem um contexto material e, na verdade, um espaço e um lugar, bem como um conjunto de recursos simbólicos (WOODWARD, 2014, p. 30).

No contexto social contemporâneo, em que o trabalho assume cada vez mais importância na vida dos indivíduos, a representação de "trabalhador" ganha lugar de destaque entre os papéis assumidos pelo sujeito (JAQUES, 1996), uma vez que as organizações assumem posição relevante entre os grupos com os quais se quer identificar. Apesar da realidade descrita por Bauman (2005), cuja tendência é de formação de grupos que são "frágeis 'totalidades virtuais', em que é fácil entrar e ser abandonado" (BAUMAN, 2005, p.31), as organizações tendem a oferecer mais segurança e estabilidade nesse sentido, e passam, portanto, a se apresentar como "produtoras de identidades sociais" (FREITAS, 2006, p.58).

Hoje, frente ao esfalecimento do Estado [...], qual o discurso de relevância que resta ao sujeito? Diante da anemia coletiva proveniente de toda esta perturbação dos processos anteriormente possíveis de identificação, fica fácil para que o discurso das grandes corporações construa um novo imaginário coletivo. Seu pleno potencial identitário mostra-se capaz uma vez que as corporações produzem um sentido para existência do sujeito - além de conseguir tangibilizar tal narrativa em seus produtos ou serviços, de forma palpável. Hoje, é com grande facilidade que nota-se o valor do 'sobrenome corporativo' (CAPPELLANO, 2014, p. 41).

Assim, é comum que, quando interpelado pela questão "Quem é você?”, o sujeito responda seu nome seguido da empresa em que trabalha. Como afirma Freitas (2006),

as significações imaginárias sociais tornam central a função da identidade, do reconhecimento e do pertencimento sociais. Essa função, antes preenchida pelo social, parece agora deslocar-se para as organizações e empresas, onde a carreira ou o status profissional torna-se a grande referência da identidade social que vai falar mais alto no psiquismo dos indivíduos (FREITAS, 2006, p.59).

Adicionalmente, Silva (2014) afirma que é a criação linguística que define, ativamente, no 
contexto das relações culturais e sociais, a identidade. Referenciando Ferdinand de Saussure, Silva defende que a língua é um sistema de diferenças. É por meio da linguagem que o indivíduo é colocado em uma cadeia infinita de conceitos que o permite identificar que uma palavra se refere a seu significado e, portanto, nega todos os outros possíveis (SILVA, 2014). Ainda assim, o significado daquilo que se produz na linguagem é instável e pode gerar interpretações diferentes da desejada, apesar do esforço natural de se fazer entender perfeitamente sempre que se fala.

A língua precede o sujeito, portanto, a ordem natural é de que este se adapte àquela. É submetido às regras da língua e dos sistemas culturais que se pode produzir significados, que surgem "nas relações de similaridade e diferença que as palavras têm com as outras no interior do código da língua" (HALL, 2014b, p. 25). Neste sentido, sendo a língua um sistema social e não individual, o processo de identificação é uma relação social e está submetido às relações de poder ${ }^{4}$ (SILVA, 2014).

As posições que os sujeitos assumem nos processos de identificação não são, portanto, necessariamente individuais. Há recorrentes posições-de-sujeito que estão vinculadas a grupos de maior ou menor envergadura, mas que estabelecem, igualmente, seus limites por meio da identidade e da diferença. "Nós somos 'nós' porque não somos 'eles"”. Neste caso, coletivo, evidenciam-se claramente as relações de poder, pois, presume-se uma classificação entre quem faz e quem não faz parte.

Surgem, por conseguinte, práticas coletivas que estabelecem um sistema de significações para ações e linguagens próprias, que passam a identificar e definir características de reconhecimento a estes grupos e os indivíduos que deles fazem parte. Neste sentido, Freitas (2006) afirma que a identidade, por não ser fixa, depende do seu ponto de definição, podendo estar relacionada ao indivíduo, a um grupo ou à sociedade em geral.

Um sujeito tem diversas identidades, e o conjunto delas lhe permite experimentar um sentimento de identidade, visto que não existe identidade sem esse sentimento interno. Este é composto dos sentidos de unidade, de singularidade, de coerência, de filiação ou pertencimento, de valor, de autonomia e confiança, organizados em torno de uma vontade de existência (FREITAS, 2006, p. 40).

É reconhecendo-se nesses grupos que o indivíduo se insere num sistema cultural, que garantirá o compartilhamento de significados às representações próprias daquele ambiente. “Todo grupo acaba desenvolvendo seu próprio 'código', pelo qual tudo pode ser compreendido por meias palavras ou mesmo pelo silêncio" (FREITAS, 2006, p. 31).

\section{O PROCESSO DE IDENTIFICAÇÃO DO PROFISSIONAL DE COMUNICAÇÃO}

Sendo o processo de identificação contínuo e inerente ao indivíduo ao longo de sua vida,

\footnotetext{
${ }^{4}$ Segundo Silva, as marcas da presença do poder são “incluir/excluir ('estes pertencem, aqueles não'); demarcar fronteiras ('nós' e 'eles'); classificar ('bons e maus'; 'puros e impuros'; 'desenvolvidos e primitivos'; 'racionais e irracionais'); normalizar ('nós somos normais; eles são anormais')” (2014, p.81-82).
} 
independentemente da posição que esteja ocupando, não importa a posição-de-sujeito, nunca haverá uma em que se deseje (ou possa) fixar. Em se tratando da identificação com as organizações, a fragmentação da identidade se fortalece nos programas de "flexibilidade" de trabalho recentemente adotados pelas empresas, tendência que vem aumentando a quantidade de contratos de emprego de curto prazo ${ }^{5}$. Adicionalmente, segundo Bauman, "um jovem americano com nível médio de educação espera mudar de emprego 11 vezes durante sua vida de trabalho" (2001, p.185), o que evidencia a temporalidade da identidade que a corporação lhe confere.

Ao atuar em um cargo cujas responsabilidades e atribuições não são extremamente claras nem aos executivos do mais alto escalão das organizações (FERRARI, 2009), o profissional de comunicação tem acentuado seu processo de identificação, ao precisar se apegar às diferentes interpelações que lhe são postas acerca do trabalho que realiza. Ou seja, adicionalmente ao processo contínuo e natural de identificação do sujeito contemporâneo, o profissional de comunicação corporativa padece também da confusão de seus interlocutores - e, por vezes, sua também - a respeito do trabalho que desempenha.

\begin{abstract}
A comunicação foi e ainda é confundida pela alta direção na medida em que muitos executivos não a veem como um processo contínuo e permanente de construção de sentidos e significados que se traduzem em percepções e opiniões da sociedade para as organizações. As entrevistas por nós realizadas com os CEOs de empresas mostram que a visão deles está centrada na comunicação vista como 'instrumento' e como ‘meio' tangível para conseguirem benefícios concretos para seus negócios (FERRARI, 2009, p.155).
\end{abstract}

Segundo a autora, a história da comunicação ajuda a explicar a realidade vivida pelo profissional nas organizações. "Uma das razões dessa situação parece ter origem no consenso entre os primeiros pesquisadores de que o campo da comunicação teria uma estreita vinculação com os meios massivos de informação" (FERRARI, 2009, p.155).

Concorda com a afirmação Mansi ao dizer que

A comunicação com empregados é um espaço relativamente recente dentro do campo da comunicação organizacional que, por sua vez, também não carrega muitas décadas de existência. Ambas têm sua origem na prática. Talvez resida aí uma característica muito marcante da função: seu aspecto instrumental (MANSI, 2014, p.10).

Fernandes atribui tal característica à relação (ou à falta dela) entre academia e mercado.

A universidade brasileira fundamenta relações públicas na vertente humanista administrativa; em contrapartida, o mercado segue a escola norte-americana e caminha no mesmo sentido de direção. [...] A universidade comete o pecado capital de buscar incessantemente sua integração com o mercado, que não dá a menor importância aos fundamentos teóricos ministrados por ela. Apesar de todos os esforços, não existe nenhuma ponte entre o ensino e a prática de relações públicas, pois os próprios alunos se curvam ao imperialismo do mercado, abandonando os princípios e

\footnotetext{
${ }^{5}$ Para Bauman (2001), o termo 'flexibilidade' "quando aplicado ao mercado de trabalho augura um fim do 'emprego como conhecemos', anunciando em seu lugar o advento do trabalho por contratos de curto prazo, ou sem contratos, posições sem cobertura previdenciária, mas com cláusulas 'até nova ordem”” (BAUMAN, 2001, p.185).
} 
fundamentos aprendidos na universidade. E, por razões inexplicáveis, ao deixarem a universidade, recomeçam o aprendizado submetendo se às regras e práticas impostas por ele (FERNANDES, 2011, p. 46-47).

Não havendo clareza no mercado sobre a atividade principal a qual o profissional de comunicação deve responder, a categoria como um todo se fragmenta e, portanto, enfraquece. A pesquisa da Aberje (2012) mostra que vem diminuindo a quantidade de empregados que trabalham em comunicação interna nas organizações pesquisadas.

A reflexão proposta por Fernandes (2011) dá pistas sobre os motivos deste enfraquecimento da prática da comunicação que se observa nas organizações. A profissão de relações públicas se estabeleceu no fim da década de 60 para dar conta da demanda de comunicação corporativa que o mercado vinha apresentando há pelo menos 20 anos. Neste período sem um profissional de formação específica e sem regulamentação da atividade profissional, jornalistas, publicitários e outros profissionais assumiram este posto nas organizações. Praticamente desde sua formalização, as relações públicas, enquanto categoria profissional, passaram reivindicando um espaço exclusivo no gerenciamento da comunicação das organizações, sem - aparentemente - reconhecer que a demanda empresarial não está vinculada à formação acadêmica.

Dividida, a categoria dos profissionais de relações públicas experiencia, há anos, uma polarização sobre a regulamentação da profissão. Há, entre esses profissionais, aqueles que defendem uma maior fiscalização nas organizações para garantir uma reserva de mercado - no desenvolvimento da comunicação corporativa - a quem se formar nos cursos de graduação em relações públicas. Do outro lado, há um grupo de profissionais que argumenta que esta regulamentação, por não refletir a realidade do mercado de trabalho, deveria ser flexibilizada, para valorizar, desta maneira, a atuação efetiva das relações públicas, enquanto disciplina organizacional, para além da formação universitária.

Neste embate entre proposição acadêmica e práxis, a atividade de comunicação organizacional tem dificuldade de se sedimentar, ainda mais na realidade contemporânea fragmentada. É, então, em muitos casos, relegada a uma categoria profissional que Robert Reich (apud BAUMAN, 2001) chama de "trabalhadores de rotina".

Hoje em dia tendem a ser as partes mais dispensáveis, disponíveis e trocáveis do sistema econômico. Em seus requisitos de emprego não constam nem habilidades particulares, nem a arte da interação social com clientes - e assim são as mais fáceis de substituir; têm poucas qualidades especiais que poderiam inspirar seus empregadores a desejar mantê-los a todo custo; controlam, se tanto, apenas parte residual e negligencial do poder de barganha (BAUMAN, 2001, p.191).

Paradoxalmente, este profissional, com acentuada dificuldade no processo de identificação e frequente designação meramente técnica e operativa, comumente se responsabiliza pela construção do discurso organizacional. A ele é designada a responsabilidade de produzir ou decodificar os interesses 
corporativos e encontrar formas assertivas de transmiti-lo adequada e coerentemente aos empregados da organização a qual está vinculado.

O trabalho do profissional que responde pela área de comunicação, portanto, abrange a tarefa de auxiliar o processo de identificação dos demais empregados da organização, uma vez que o discurso adotado nos processos midiáticos faz o papel do Outro, em nome da empresa, na construção da identidade de todos aqueles que trabalham para uma organização.

\section{CONSIDERAÇÕES FINAIS}

A sociedade está se transformando em uma velocidade nunca antes vista. Não há na história período de mudança nas relações sociais tão significativas que tenha acontecido em tão pouco tempo quanto na sociedade contemporânea. Indivíduos inseridos em uma sociedade em transformação são afetados por essas mudanças, ao mesmo tempo em que são responsáveis por elas. Buscam incessantemente se reconhecer em diferentes representações, que os posicionem em consonância com grupos aos quais fazem (ou querem fazer) parte.

Com o presente artigo buscou-se investigar como os profissionais de comunicação nas empresas se submetem aos processos de identificação e em quais instâncias a confusão de sua atuação na práxis profissional pode afetar seu processo de reconhecimento e identificação em determinados sistemas sociais.

É no realizar da sua atividade que o profissional está construindo sua identidade - e a da categoria como um todo. As posições a que se apega durante sua atuação terão contribuição direta para aquelas que surgirão em seguida, seja na organização em que atua ou nas próximas que potencialmente atuará.

As referências bibliográficas e estudos realizados pelos autores aqui citados contribuíram para esta reflexão que perpassa pelo próprio reconhecimento da atividade de comunicação corporativa e da categoria de relações públicas pelo mercado. A confusão aqui mencionada, evidenciada pelas pesquisas de Ferrari (2009), é apenas um reflexo de um processo histórico da atividade.

Com este artigo, abre-se, ainda, a possibilidade de outra reflexão a respeito do discurso organizacional que está sendo transmitido aos empregados. Teria o profissional de comunicação - ou o processo de comunicação corporativa como um todo - parte representativa de responsabilidade pela alta rotatividade de emprego observada na contemporaneidade? A reflexão a este tema cria espaço para um novo artigo acadêmico que passe pelas ideias paradoxais de, por um lado, as organizações terem assumido um papel relevante, enquanto instituições sociais, nos processos de identificação do sujeito contemporâneo e, por outro, a acentuada mobilidade de emprego de trabalhadores das mais diversas áreas, eventualmente como uma forma de 'evitar frustração iminente [...], uma reação natural à 'flexibilidade' do mercado de trabalho" (BAUMAN, 2001, p. 191). 


\section{REFERÊNCIAS}

ABERJE, Associação Brasileira de Comunicação Empresarial,. (2012). $4^{a}$ Pesquisa comunicação interna. São Paulo: ABERJE. from http://www.aberje.com.br/pesquisa/PesquisaComunicacaoInterna2012.pdf

Baldissera, R. (2010). A complexidade dos processos comunicacionais e interação nas organizações. In M. Marchiori, Faces da cultura e da comunicação organizacional. vol. 2 (1st ed.). São Caetano do Sul, SP: Difusão.

Bauman, Z. (2001). Modernidade líquida. Rio de Janeiro: Zahar.

Bauman, Z. (2005). Identidade. Rio de Janeiro: J. Zahar.

Cappellano, T. (2014). Psicanálise e linguagem na cultura organizacional (Especialização em Semiótica Psicanalítica - Clínica da Cultura). Pontifícia Universidade Católica de São Paulo.

Carramenha, B., Cappellano, T., \& Mansi, V. (2013). Comunicação com empregados: a comunicação interna sem fronteira. Jundiaí, SP: In House.

Durand, J. (2006). Educação e ideologia do talento no mundo da publicidade. Cad. Pesqui., 36(128). doi:10.1590/s0100-15742006000200008

Farias, L. (2011). Planejamento e estratégia: bases do trabalho em relações públicas. In L. Farias,Estratégia em Relações Públicas - Técnicas, conceitos e instrumentos (1st ed.). São Paulo: Summus.

Fernandes, B. (2011). História das relações públicas: surgimento e consolidação na América do Sul. In L. Farias, Estratégia em Relações Públicas - Técnicas, conceitos e instrumentos (1st ed.). São Paulo: Summus.

Ferrari, M. (2009). Cenário latino-americano da comunicação e Relações Públicas. In M. Ferrari, J. Grunig \& F. França, Relações Públicas: teoria, contexto e relacionamentos (1st ed.). São Caetano do Sul: Difusão.

Freitas, M. (2006). Cultura Organizacional: identidade, sedução e carisma (5th ed.). Rio de Janeiro: FGV.

Gregolin, M. (2008). Identidade: objeto ainda não identificado. Revista Estudos Da Língua, 6(1), 81-97.

Hall, S. (2013). Da diáspora: identidades e mediações culturais. Belo Horizonte: UFMG.

Hall, S. (2014a). In T. Silva, Identidade e diferença: a perspectiva dos Estudos Culturais (14th ed.). Petrópolis: Vozes.

Hall, S. (2014b). A identidade cultural na pós-modernidade. Rio de Janeiro: Lamparina.

Hime, G. (2004). Na fundação da primeira escola de jornalismo do Brasil, Cásper Líbero gera o conceito de jornalismo moderno. Revista PJ:BR Jornalismo Brasileiro, (3). Retrieved from http://www2.eca.usp.br/pjbr/arquivos/artigos3_b.htm 
Jacques, M. (1996). Identidade e trabalho: uma articulação indispensável. Trabalho, Organizações E Cultura, 11, 21-26.

Kunsch, M. (2002). História das Relações Públicas no Brasil: retrospectiva e aspectos relevantes. Idade Mídia, 1(2). Retrieved from http://www.portal-rp.com.br/bibliotecavirtual/memoria/0242.pdf

Kunsch, M. (2003). Planejamento de relações públicas na comunicação integrada (5th ed.). São Paulo: Summus.

Mansi, V. (2014). Comunicação, diálogo e compreensão: narrativas de liderança (Mestrado). Faculdade Cásper Líbero.

Marchiori, M. (2008). Cultura e comunicaçação organizacional: um olhar estratégico sobre a organização (2nd ed.). São Caetano do Sul: Difusão Editora.

Martino, L. (2014). Teoria da Comunicação: ideias, conceitos e métodos (5th ed.). Petrópolis: Vozes.

Nassar, P. (2009). Conceitos e processos de comunicação organizacional. In M. Kunsch, Gestão estratégica em comunicação organizacional e relações públicas (2nd ed.). São Caetano do Sul: Difusão.

SEBRAE, Serviço Brasileiro de Apoio às Micro e Pequenas Empresas,. (2013). Anuário do trabalho na micro $e$ pequena empresa. São Paulo: DIEESE. Retrieved from http://www.sebrae.com.br/Sebrae/Portal\%20Sebrae/Anexos/Anuario\%20do\%20Trabalho\%20Na\%20M icro\%20e\%20Pequena\%20Empresa_2013.pdf

Silva, T. (2014). A produção social da identidade e da diferença. In T. Silva, Identidade e diferença: $a$ perspectiva dos Estudos Culturais (14th ed.). Petrópolis: Vozes.

Tatit, L. (1997). Eu sou eu. São Paulo: Dalibu.

Vieira, N. de P. . (2021). Atos de fala performáticos e a produção de identidades fragmentadas. Latin American Journal of Development, 3(1), 163-174. https://doi.org/10.46814/lajdv3n1-018

Woodward, K. (2015). Identidade e diferença: uma introdução teórica e conceitual. In T. Silva,Identidade e diferença: a perspectiva dos Estudos Culturais (14th ed.). Petrópolis: Vozes. 